\title{
Tabletop transient collisional excitation x-ray lasers
}

\author{
J. Dunn, Y. Li, A.L. Osterheld, J. Nilsen, S.J. Moon, K.B. \\ Fournier, J.R. Hunter, A. Ya. Faenov, T.A. Pikuz, V.N. \\ Shlyaptsev
}

This article was submitted to International Society for Optical Engineering Conference on Soft XRay Lasers and Application III, Denver, CO, July 19-20, 1999

\section{September 3, 1999}

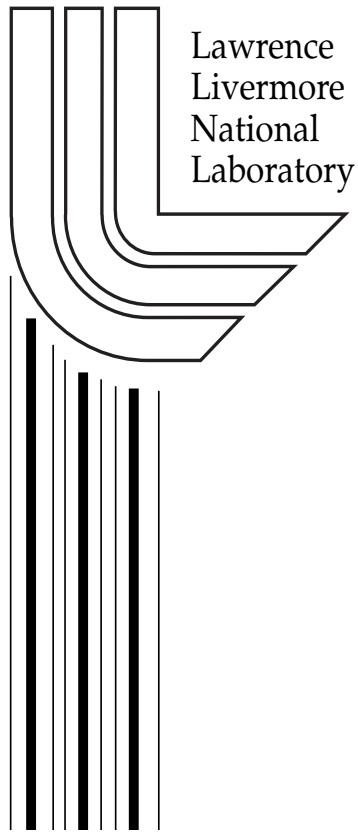




\section{DISCLAIMER}

This document was prepared as an account of work sponsored by an agency of the United States Government. Neither the United States Government nor the University of California nor any of their employees, makes any warranty, express or implied, or assumes any legal liability or responsibility for the accuracy, completeness, or usefulness of any information, apparatus, product, or process disclosed, or represents that its use would not infringe privately owned rights. Reference herein to any specific commercial product, process, or service by trade name, trademark, manufacturer, or otherwise, does not necessarily constitute or imply its endorsement, recommendation, or favoring by the United States Government or the University of California. The views and opinions of authors expressed herein do not necessarily state or reflect those of the United States Government or the University of California, and shall not be used for advertising or product endorsement purposes.

This is a preprint of a paper intended for publication in a journal or proceedings. Since changes may be made before publication, this preprint is made available with the understanding that it will not be cited or reproduced without the permission of the author.

This report has been reproduced

directly from the best available copy.

Available to DOE and DOE contractors from the

Office of Scientific and Technical Information

P.O. Box 62, Oak Ridge, TN 37831

Prices available from (423) 576-8401

http://apollo.osti.gov/bridge/

Available to the public from the

National Technical Information Service

U.S. Department of Commerce

5285 Port Royal Rd.,

Springfield, VA 22161

http://www.ntis.gov/

OR

Lawrence Livermore National Laboratory

Technical Information Department's Digital Library

http://www.llnl.gov/tid/Library.html 


\title{
Tabletop transient collisional excitation $x$-ray lasers
}

\author{
J. Dunn, Y. Li ${ }^{1}$, A.L. Osterheld, J. Nilsen, S.J. Moon, K.B. Fournier, \\ J.R. Hunter, A. Ya. Faenov ${ }^{2}$, T.A. Pikuz ${ }^{2}$, and Vyacheslav N. Shlyaptsev 3 \\ Lawrence Livermore National Laboratory, Livermore, CA 94551 \\ ${ }^{1}$ ILSA, Lawrence Livermore National Laboratory, Livermore, CA 94551 \\ 2 VNIIFTRI, Mendeleevo, Moscow Region, 141570, Russia \\ 3 Dept. of Applied Science, University of California Davis-Livermore, Livermore, CA 94551
}

\begin{abstract}
Recent transient collisional excitation $\mathrm{x}$-ray laser experiments are reported using the COMET tabletop laser driver at the Lawrence Livermore National Laboratory (LLNL). Ne-like and Ni-like ion x-ray laser schemes have been investigated with a combination of long $600 \mathrm{ps}$ and short $\sim 1$ ps high power laser pulses with $5-10 \mathrm{~J}$ total energy. We show small signal gain saturation for $\mathrm{x}$-ray lasers when a reflection echelon traveling wave geometry is utilized. A gain length product of 18 has been achieved for the Ni-like Pd $4 d \rightarrow 4 p J=0-1$ line at $147 \AA$, with an estimated output of $\sim 10 \mu \mathrm{J}$. Strong lasing on the $119 \AA$ Ni-like Sn line has also been observed. To our knowledge this is the first time gain saturation has been achieved on a tabletop laser driven scheme and is the shortest wavelength tabletop x-ray laser demonstrated to date. In addition, we present preliminary results of the characterization of the line focus uniformity for a Ne-like ion scheme using L-shell spectroscopy.
\end{abstract}

Keywords: $\quad$ x-ray laser, transient collisional excitation, x-ray spectroscopy, Ne-like, Ni-like.

\section{INTRODUCTION}

High output, tabletop x-ray lasers have developed rapidly in the last five years. The inherent advantages of higher efficiency, reduced size, low cost and high repetition rate are scientifically attractive but are also important for future development of applications in this field. Significant progress has been made in the fast capillary discharge scheme operating at $469 \AA$ for collisionally pumped Ne-like Ar. Gain saturation has been shown by double-passing with a half cavity and recently this has been extended to high repetition rate, high average power operation. ${ }^{1}$ A $10 \mathrm{~Hz}$ Pd-like ion x-ray laser scheme has been demonstrated with $\mathrm{gL} \sim 11$ at $418 \AA$ for $40 \mathrm{fs}$ irradiation of a xenon gas cell using field-induced tunneling ionization followed by collisional excitation. ${ }^{2}$ The transient collisional excitation scheme as described by Afanasiev and Shlyaptsev has been proposed to achieve tabletop operation for laser-driven schemes. ${ }^{3}$ This utilizes two laser pulses where a long nanosecond pulse at $10^{12}$ $\mathrm{W} \mathrm{cm}{ }^{-2}$ generates the plasma and creates the required closed shell Ne-like or Ni-like ionization conditions. After a delay to allow for plasma cooling and expansion which is desirable for both optimum pumping and ray propagation along the plasma column, a second much shorter 1 ps laser pulse at $10^{15} \mathrm{~W} \mathrm{~cm}^{-2}$ rapidly generates a transient population inversion. The fast timescale of a few picoseconds for the rapid heating is of order of the collisional redistribution of the excited levels and allows efficient pumping without perturbing the ionization. This produces very high $\mathrm{x}$-ray laser gains predicted to be greater than $100 \mathrm{~cm}^{-1}$ and the possibility of saturation for target lengths of less than $1 \mathrm{~cm}$. The advantage with this scheme is that less than $5-10 \mathrm{~J}$ of laser energy from a chirped pulse amplification (CPA) tabletop laser is required to drive the inversion provided the transient gain conditions are optimized. The initial experimental demonstration of the transient scheme was shown for Ne-like Ti $3 p \rightarrow 3 s$ transition at $326 \AA \AA^{4}$ This has been extended to the Ni-like ion sequence for the Pd $4 d \rightarrow 4 p$ line at $146.8 \AA .{ }^{5}$ Gain 
saturation was first reported on the Ne-like transient scheme for Ti at $326 \AA$ and Ge at $196 \AA$ using the larger Vulcan-CPA laser at the Rutherford Appleton Laboratory. ${ }^{6}$ However, the laser drive energy to achieve this saturation was reported to be a total of $32 \mathrm{~J}$ and $60 \mathrm{~J}$, respectively for $\mathrm{Ti}$ and $\mathrm{Ge}$, which is currently beyond the output of present table-top lasers.

In this paper and accompanying papers ${ }^{7,8}$ we describe recent experimental progress at LLNL to drive various Ne-like and Ni-like x-ray lasers into saturation by using a traveling wave scheme. We report very high gains, up to $65 \mathrm{~cm}^{-1}$ for the $\mathrm{Pd} 4 d \rightarrow 4 p$ line at $146.8 \AA$, and determine the gain length product $>18$. We have also observed strong lasing for Mo, Ag, Cd and Sn targets. We present preliminary results for characterization of the line focus uniformity for Fe targets and this is discussed further by Moon et al. ${ }^{8}$

\section{EXPERIMENTAL DESCRIPTION}

The experiments were performed on the Compact Multipulse Terawatt (COMET) laser system at LLNL. ${ }^{9}$ This laser, operating at $1054 \mathrm{~nm}$ wavelength, utilizes the technique of chirped pulse amplification to produce two beams of nominally $500 \mathrm{fs}$ (compressed) and $600 \mathrm{ps}$ (FWHM) pulse duration with a repetition rate of 1 shot every 4 minutes. For this work, the short pulse was lengthened to $1.0-1.5$ ps with energy of $4.5-5.5 \mathrm{~J}$ while the long pulse energy was typically $0.5 \mathrm{~J}$ to $2.2 \mathrm{~J}$ delivered in the line focus at the target chamber. The laser spectrum, energy in the two laser pulses, the short pulse near-field beam profile, the pulseshapes and relative delay were monitored on every shot. For the Ni-like ion X-ray lasers, the peak-to-peak delay between the laser pulses was found to be optimal at $700 \mathrm{ps}$ with the short pulse arriving after the long pulse. The line focus length of slightly longer than $1 \mathrm{~cm}$ was achieved by using a cylindrical lens in combination with an on-axis paraboloid.
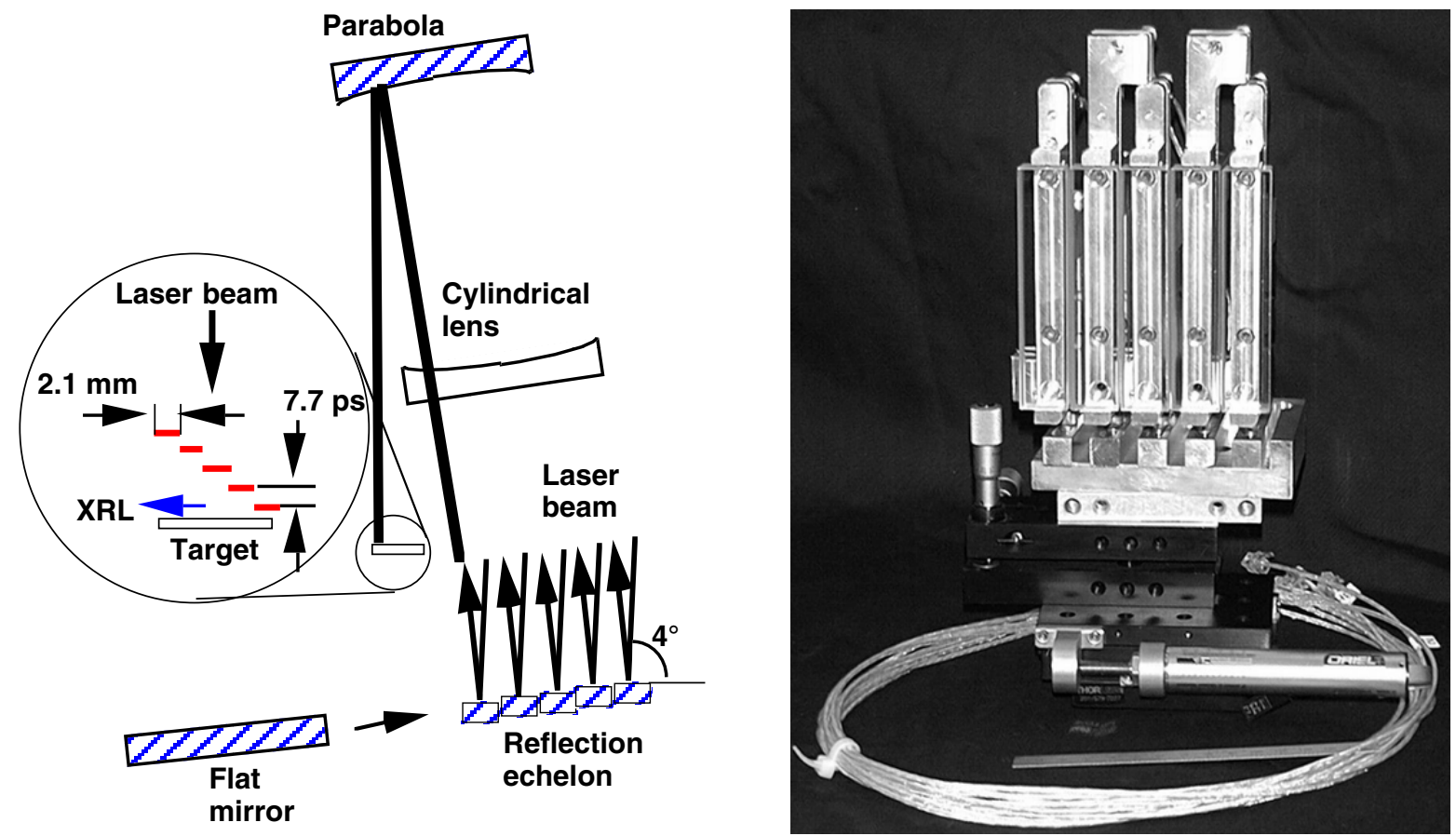

Fig. 1 (Left) Experimental setup showing focusing optics and 5-step reflection echelon for traveling wave excitation. Reflection echelon can be replaced with flat mirror in which case short pulse arrives simultaneously along the line focus.

Fig. 2 (Right) Photograph showing 5-step reflection echelon. Total reflecting surface area is $10.2 \times 10.2$ $\mathrm{cm}^{2}$. 
A 1200 line $\mathrm{mm}^{-1}$ variable-spaced flat-field grating spectrometer with a back-thinned $1024 \times 1024$ chargecoupled device $(\mathrm{CCD})$ readout observed the $\mathrm{x}$-ray laser output on axis. A gold-coated cylindrical and flat mirror collection optic on this spectrometer imaged the plasma across the vertical width of the line focus with 1:1 magnification onto a $500 \mu \mathrm{m}$ wide entrance slit. Fiducial wires were placed close to the spectrometer entrance slit and aligned to the target surface with a telescope to calibrate the angular deflection and beam divergence of the $\mathrm{x}$ ray laser in the horizontal direction. Flat polished, high-purity target slabs were used in the experiment and tilted back by $2-5 \mathrm{mrad}$ in the horizontal direction to compensate for refraction of the x-ray laser in the plasma column. A CCD x-ray slit camera with $25 \mu \mathrm{m}$ spatial resolution monitored the line focus plasma uniformity and overlap of the laser pulses. An on-axis soft $\mathrm{x}$-ray multilayer-coated imaging system spatially resolved the 2-dimensional $\mathrm{x}$-ray laser beam exit profile and output energy for the $189 \AA$ Ni-like Mo $4 d \rightarrow 4 p$ laser. 7

Several changes in the experimental conditions were introduced in comparison with our previous $\mathrm{x}$-ray laser campaigns. ${ }^{5,9}$ First, the long pulse was defocused to a width of approximately $150 \mu \mathrm{m}$ (FWHM) while the short pulse beam was focused to $80 \mu \mathrm{m}$. The main idea was to produce a more uniform lateral plasma medium prior to the excitation process driven by the picosecond laser. Furthermore, this made the overlap of the two laser line foci less sensitive to small alignment errors. Secondly and more importantly, a traveling wave excitation geometry was introduced to increase the laser output and mitigate against the reduced amplification at longer target lengths resulting from the short-lived transient gain lifetime. The traveling wave excitation geometry was implemented before the focusing optics by using a high-reflectivity, $0^{\circ}$ dielectric-coated reflection echelon consisting of five flat vertical mirror segments. This layout is shown in Fig. 1 and a photograph of the reflection echelon is presented in Fig. 2, previous page. Each segment was offset by $1.2 \mathrm{~mm}$ relative to the adjacent mirror in the direction away from the optical axis of the laser drive beam. This introduced a delay of 7.7 ps per step, corresponding to $c$ across the line focus length, matched to the propagation of the x-ray laser in the gain region with a preferred direction towards the flat-field spectrometer. For non-traveling wave excitation the reflection echelon was replaced with a flat high reflectivity mirror, see Fig. 1. Optical streak camera measurements at the line focus with the short pulse beam confirmed that the flat mirror setup produced simultaneous excitation along the line focus corresponding to infinite $c$, and therefore no partial intrinsic traveling wave. It should be noted that a reflection echelon design was reported for a short pulse laser scheme previously. ${ }^{10}$ However, no significant effect on the spectra was observed in that work. In contrast, the traveling wave reflection echelon reported here gave a dramatic enhancement in the output of all of our x-ray lasers.

\section{EXPERIMENTAL RESULTS}


Gain saturation with microJoule output for the $\mathrm{Ni}$ like Mo $4 d \rightarrow 4 p$ transition at $189 \AA$ using the same traveling wave technique is described in these proceedings. ${ }^{7}$ Here, we report the experimental details of the Ni-like Pd $4 d \rightarrow 4 p$ x-ray laser line at $146.8 \AA$ with and without the traveling wave. Previously, strong lasing, gain of $35 \mathrm{~cm}^{-1}$ and a gain length product of 12.5, was observed under slightly different laser irradiation conditions. ${ }^{5}$ However, the x-ray laser was not reported to be in the saturation regime largely because of the finite transient gain lifetime and no traveling wave excitation geometry. Fig. 3 (right) shows the $\mathrm{x}$-ray laser intensity versus length in a recent experiment. The typical laser energy at the line focus is $1.5-1.8 \mathrm{~J}$ in the long pulse and $5.2 \mathrm{~J}$ in the short pulse, about $7 \mathrm{~J}$ total. The delay between the two pulses was optimized so that the short pulse arrived $700 \mathrm{ps}$ after the peak of the $600 \mathrm{ps}$ long pulse. There are a number of interesting features that can be commented upon. The data taken without the traveling wave (solid circles in Fig. 3) show a rapid increase in intensity for short target lengths, but with a distinct change at $0.3-0.4 \mathrm{~cm}$. Target lengths above $0.4 \mathrm{~cm}$ show a significantly reduced exponentiation. In contrast, the data taken with the traveling wave (open circles) shows that the x-ray laser intensity strongly and smoothly increases beyond $0.4 \mathrm{~cm}$ lengths. Thus, the $\mathrm{x}$-ray

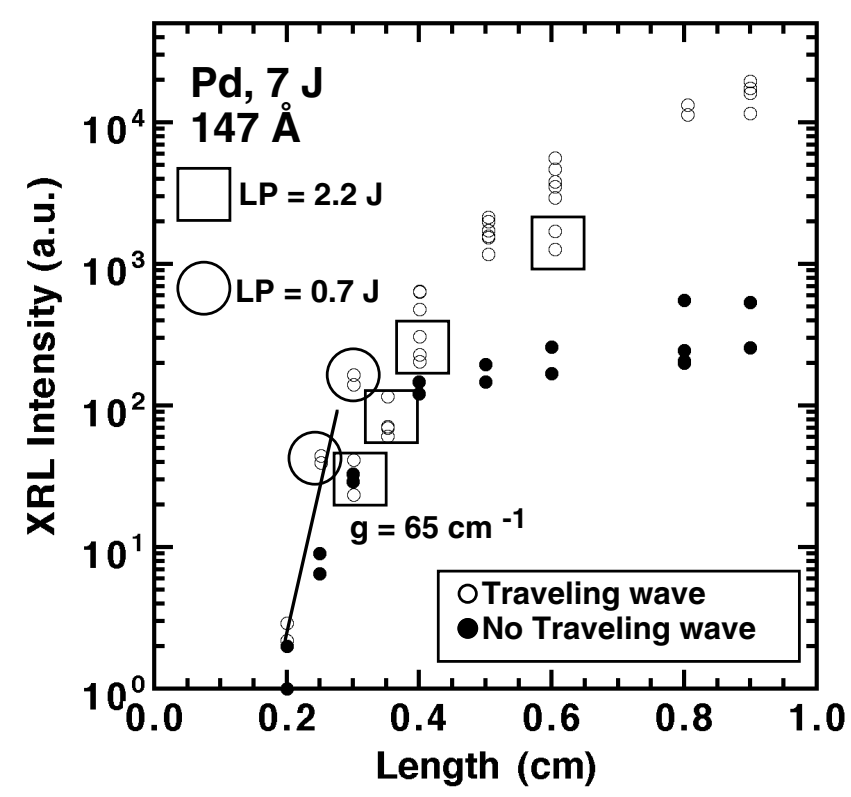

Fig. $3 \mathrm{X}$-ray laser intensity versus length plot for the Nilike $\mathrm{Pd} 4 d \rightarrow 4 p$ x-ray laser line at $147 \AA$ with the traveling wave (open circles) and without the traveling wave (closed circles). Nominal energy in the line focus is $1.8 \mathrm{~J}$ in long pulse (LP) and $5.2 \mathrm{~J}$ in short pulse (SP). 
laser intensity with the reflection echelon is enhanced by $20-100 \times$ higher than no traveling wave at $0.8-0.9 \mathrm{~cm}$ lengths. This establishes that the main reason for the rollover in the output for the data taken without the traveling wave is related to the finite transient gain lifetime in the plasma column and not due to refraction effects. ${ }^{5}$ Applying the Linford equation to the traveling wave data points indicates that the gain is as high as $65 \mathrm{~cm}^{-1}$, as shown by the solid line through data points for 0.2 to 0.3 cm. ${ }^{11}$

The second interesting feature relates to the observed trend in the $\mathrm{x}$-ray laser output when the long pulse energy is set between approximately 0.7 and $2.2 \mathrm{~J}$. It should be noted that the delay between the laser pulses and the short pulse energy were maintained constant. Increasing the long pulse energy by $50 \%$, from $1.5 \mathrm{~J}$ to $2.2 \mathrm{~J}$ or more, gives a systematic reduction in the x-ray laser output. Those data points with higher long pulse energy are enclosed within a square, see Fig. 3, where the output is generally lower by a factor of two to three times. The remaining laser output data are better grouped with significantly less scatter. If the long pulse energy is reduced to $0.7 \mathrm{~J}$ then an increase is observed in the $\mathrm{x}$-ray laser output for shorter target lengths of $0.3 \mathrm{~cm}$ or lower. This effect becomes less significant at longer targets, but contributes to high gain that is determined for $0.3 \mathrm{~cm}$ or less. Reduced refraction effects are predicted to be the main factor here; this is currently being investigated further in the data analysis and in kinetics and hydrodynamic simulations. A gain length product of $\sim 18$ at $0.9 \mathrm{~cm}$ target length is estimated. This is in agreement with the 2 orders of magnitude increase that is observed with the traveling wave. We have measured the absolute output energy of the Ni-like Mo $189 \AA$ A line using the multilayer imaging system. ${ }^{7}$ Output energy of $2.5-5 \mu \mathrm{J}$ is estimated for the Mo line when the detector quantum efficiency, multilayer reflectivity, and filter transmission is included. The $147 \AA \mathrm{Pd}$ line is several times stronger than the Mo line based on the comparisons of the spectra recorded by the flat-field spectrometer. Therefore, by including the relative sensitivity of the spectrometer at the two wavelengths in the analysis, we can conservatively estimate the Pd x-ray laser output as $10 \mu \mathrm{J}$.

Fig. 4 presents single shot $\mathrm{x}$-ray laser spectra recorded with the on-axis flat-field spectrometer for $0.9 \mathrm{~cm}$ laser targets irradiated with the traveling wave excitation. The energy at the line focus for the long pulse/short pulse for each shot was as follows: Mo 0.7 J/5.3 J; Pd1.6 J/4.8 J; Ag1.5 J/4.7 J; Cd $1.7 \mathrm{~J} / 4.85 \mathrm{~J} ;$ Sn $1.7 \mathrm{~J} / 5.0 \mathrm{~J}$, respectively. Typically $7 \mathrm{~J}$ total energy was used. For the Pd spectrum, a $2000 \AA$ Lexan and $750 \AA$ Al foil was placed in front of the spectrometer to give a $25 \times$ attenuation on the $147 \AA \mathrm{x}$-ray laser line and prevent detector saturation. The strongest lasing was observed for the Mo, Pd and $\mathrm{Ag}$ targets that were driven into the saturation regime. An intensity versus length scan was not conducted for $\mathrm{Ag}$. The $139 \AA \mathrm{Ag} \mathrm{x}$-ray laser was approximately 3 times lower intensity relative to the $\mathrm{Pd}$ intensity. The higher $\mathrm{Z}$ materials of $\mathrm{Cd}$ and $\mathrm{Sn}$ also lased strongly but show progressively lower output: relative to the strong $\mathrm{Pd} 4 d \rightarrow 4 p$ line: the $\mathrm{Cd}$ line at $131.5 \AA$ was a factor of 15 times lower while the $\mathrm{Sn}$ line at $119.2 \AA$ was approximately 250 times lower. The latter is the shortest wavelength $\mathrm{x}$-ray laser observed from a tabletop laser system to date. A small number of shots were tried to enhance the lasing action. Increasing the long pulse energy for Sn did not improve the output. It is speculated that the reduced output on the shorter wavelength 
lasers is possibly due to a temperature effect and lower collisional pumping from the short pulse driver. Some modest increase in the short pulse laser intensity should give stronger lasing below $120 \AA$. However, there are other options which could yield significantly higher x-ray output including further optimization of the driver conditions or the exploration of different target geometries.

\section{L-SHELL CHARACTERIZATION}

We have investigated Ne-like ion x-ray laser schemes and have performed L-shell characterization studies using Bragg crystal techniques. A high resolution spherically bent Mica (002), 2d=19.84 ̊, crystal spectrometer with radius of curvature $\mathrm{R}=150 \mathrm{~mm}$ was used in the FSSR-1D geometry to obtain both spectral and spatial resolution along the line focus. ${ }^{12}$ The $n=3 \rightarrow 2$ and $4 \rightarrow 2$ resonance line emission from a Fe target was recorded on Kodak RAR2497 film while simultaneously measuring the Ne-like $3 p \rightarrow 3 s J=0 \rightarrow 1 \mathrm{x}$-ray laser line at $255 \AA$. The line focus uniformity was also monitored with the CCD x-ray slit camera. We present preliminary spectra data here with further analysis, $\mathrm{x}$-ray lasing, comparisons and modeling to be presented elsewhere in the proceedings. ${ }^{8}$ Fig. 5 shows a spectrum recorded with a $4.8 \mathrm{~J}$ energy, $600 \mathrm{ps}$ long pulse on a $0.6 \mathrm{~cm}$ target. The peak irradiance on target is $6 \times 10^{11} \mathrm{~W} \mathrm{~cm}^{-2}$. No $\mathrm{x}$ ray laser was observed with this pulse by itself. However, this would be the typical long pulse energy used to pre-form the plasma and ionize to the Ne-like charge state before the short excitation pulse. Weak $x$-ray emission in the $15 \AA$ waveband is identified as the two strong Ne-like $3 d \rightarrow 2 p$ lines, labeled, plus additional Na-like like satellite lines to the long wavelength side. The horizontal direction gives the spatial information along the line focus and shows fairly uniform emission for the Ne-like and Na-like lines for this irradiation condition. The spectrum confirms the production of the Ne-like ion with the long pulse but no F-like is observed. Firing the short pulse after the long pulse produces strong x-ray lasing which is accompanied by F-like and $\mathrm{O}-$ like $\mathrm{Fe}$ emission in the crystal spectra.

\section{SUMMARY AND PERSPECTIVE}

The recent de-commissioning of the Nova laser facility marks the end of a chapter in laboratory x-ray lasers at LLNL. During the 1980s to the mid-1990s, the Nova x-ray laser program was the cutting edge in the field and provided the stimulus for a world-wide effort. The understanding of the x-ray laser physics has progressed fairly rapidly in the last decade and significant reduction in the laser driver required for lasing has been established. A smooth transition of $\mathrm{x}$-ray laser research at LLNL has been made away from a large facility like Nova to a small tabletop system like COMET. Therefore, it is useful to compare and contrast the Nova driver and corresponding $\mathrm{x}$ ray laser characteristics with the COMET setup. The Nova x-ray laser parameters have been derived from work described in the literature. ${ }^{13-15}$ Many of the laser parameters listed in Table 1 are approximate and are meant only 
to give some broad comparison. The transient collisional excitation scheme has allowed significant reduction in the size, cost and energy of the driver. Picosecond laser systems are available commercially and have the advantage of being operated by one person. Perhaps the main advantage of the COMET tabletop laser for $\mathrm{x}$-ray laser research is the 10-20 $\times$ higher repetition rate than NOVA. In addition, more laser shots can be performed with COMET since the lower cost of the facility allows dedicated time towards x-ray laser experiments. Gains are typically $10 \times$ higher for the transient scheme as a result of the optimized collisional pumping delivered by the $1 \mathrm{ps}$ laser. This allows the use of shorter targets of $1 \mathrm{~cm}$ or less. However, the overall $\mathrm{x}$-ray laser output is significantly lower than the workhorse Ne-like yttrium Nova x-ray laser at $155 \AA$. But again it can be noted that the COMET Ni-like Pd $146.8 \AA$ laser also operates at a similar wavelength. For many applications $10-100 \mu \mathrm{J}$ should be sufficient, particularly when the pulse length is a few picoseconds. The Ni-like Au lasing at $35 \AA$ on Nova still represents the shortest wavelength x-ray laser to be demonstrated. ${ }^{13}$ Tabletop schemes have so far worked at wavelengths as short as $119 \AA$ as discussed in this work. However, the wavelength region from $120-200 \AA$ is compatible with the Si/Mo multilayer coating technology which is robust, well-established and reasonably inexpensive. Finally, the combination of the faster picosecond pulse duration, small plasma gain cross-section region ${ }^{7}$ and better beam divergence parameters compensate for the lower output energy of the COMET x-ray lasers. An estimate of the COMET x-ray laser brightness can be made using Table 1 with a 7 ps x-ray pulse duration based on estimates of the transient gain lifetime, $80 \times 50 \mu \mathrm{m}^{2}$ gain region, and a $5 \times 5 \mathrm{mrad}^{2}$ divergence. This gives the COMET Ni-like Pd laser and Nova Ne-like Y laser an equal brightness of $10^{24} \mathrm{ph} \mathrm{mm}^{-2} \mathrm{mrad}^{-2} \mathrm{~s}^{-1}(0.01 \% \mathrm{BW})^{-1}$ assuming $\lambda / \Delta \lambda \sim 10^{4}$ in each case. The high brightness of tabletop x-ray lasers coupled with improved repetition rate will open a number of interesting applications previously not possible with the Nova x-ray laser. Picosecond pulse duration or possibly shorter into the femtosecond timescale can be explored with the transient scheme.

\begin{tabular}{|l|l|l|}
\hline \multicolumn{2}{|c|}{ COMET } & \multicolumn{1}{c|}{ Nova } \\
\hline Size & $100 \mathrm{sq} . \mathrm{ft}$ & $>40,000 \mathrm{sq} . \mathrm{ft}$ \\
Cost & $\$ 1 \mathrm{M}$ & $>\$ 100 \mathrm{M}$ \\
Pump Energy & $<10 \mathrm{~J}$ & $5-10 \mathrm{~kJ}(2$ beams, $1 \omega)$ \\
XRL Gain & $30-65 \mathrm{~cm}^{-1}$ & $1-8 \mathrm{~cm}-1$ \\
XRL Output & $>10 \mu \mathrm{J}(146.8 \AA)$ & $5 \mathrm{~mJ}(@ 155 \AA)$ \\
Shot Rate & $50-100 / \mathrm{day}$ & $4-6 / \mathrm{day}$ \\
XRL Wavelength & $119 \AA-330 \AA$ & $35 \AA-330 \AA$ \\
Pulse Duration & $5-10 \mathrm{ps}$ & $45-200 \mathrm{ps}$ \\
Brightness & $10^{24} \mathrm{ph} \mathrm{mm}^{-2} \mathrm{mrad}^{-2} \mathrm{~s}^{-1}\left(0.01 \% \mathrm{BW}^{-1}\right.$ & $10^{24} \mathrm{ph} \mathrm{m} \mathrm{mm}^{-2} \mathrm{mrad}^{-2} \mathrm{~s}^{-1}(0.01 \% \mathrm{BW})^{-1}$ \\
Cost/shot & $\$ 50-100$ & $\$ 10 \mathrm{~K}-20 \mathrm{~K}$ \\
\hline
\end{tabular}

Table 1 Comparison between the laser driver parameters and $\mathrm{x}$-ray laser characteristics generated by the transient collisional scheme using COMET and the quasi-steady state collisional excitation scheme using the Nova laser.

In summary, we have shown that the generation of strong lasing into the saturation regime can be achieved with a tabletop laser driver with less than $10 \mathrm{~J}$ energy. Implementation of the traveling wave has been the most significant improvement in attaining this result. Careful optimization of the plasma conditions for each target material is essential and small signal gains of $30-65 \mathrm{~cm}^{-1}$ are routinely determined. Characterization of the laser gain region by the use of a multilayer coated imaging system is providing valuable insight towards the transient $\mathrm{x}$ ray laser process. ${ }^{7}$ In addition, the implementation of $\mathrm{keV} \mathrm{L}$-shell imaging and spectroscopy is enhancing our understanding of the plasma conditions. ${ }^{8}$ Further work in experiments and simulations are under way.

\section{ACKNOWLEDGMENTS}


The authors would like to acknowledge the technical contributions from Bart Sellick and Al Ellis. This research was conducted at the Lawrence Livermore National Laboratory on the Physics Directorate COMET laser facility. This work was performed under the auspices of the U.S. Dept. of Energy by the Lawrence Livermore National Laboratory under Contract No. W-7405-Eng-48.

\section{REFERENCES}

1. J.J. Rocca, D.P. Clark, J.L.A. Chilla, and V.N. Shlyaptsev, "Energy Extraction and Achievement of the Saturation Limit in a Discharge-Pumped Table-Top Soft X-ray Amplifier", Phys. Rev. Lett. 77(8), 1476-1479 (1996); B.R. Benware, C.H. Macchietto, C.H. Moreno, and J.J. Rocca, "Demonstration of a high average power tabletop x-ray laser", ibid. 81(26), 5804-5807 (1998).

2. B.E. Lemoff, G.Y. Yin, C.L. Gordon III, C.P.J. Barty, and S.E. Harris, "Demonstration of a 10-Hz FemtosecondPulse-Driven XUV Laser at $41.8 \mathrm{~nm}$ in Xe IX", Phys. Rev. Lett. 74(9), 1574-1577 (1995).

3. Yu.V. Afanasiev and V.N. Shlyaptsev, Sov. J. Quant. Electron. 19, 1606 (1989); V.N. Shlyaptsev, P.V. Nickles, T. Schlegel, M.P. Kalashnikov, and A.L. Osterheld, "Table-top x-ray laser pumped with subnanosecond and picosecond pulses", SPIE Proc. 2012, 111-118 (1993).

4. P.V. Nickles, V.N. Shlyaptsev, M. Kalachnikov, M. Schnürer, I. Will, and W. Sandner, "Short Pulse X-ray Laser at $32.6 \mathrm{~nm}$ Based on Transient Gain in Ne-like Titanium", Phys. Rev. Lett. 78(14), 2748-2751 (1997).

5. J. Dunn, A.L. Osterheld, R. Shepherd, W.E. White, V.N. Shlyaptsev, and R.E. Stewart, "Demonstration of X-ray Amplification in Transient Gain Nickel-like Palladium Scheme", Phys. Rev. Lett. 80, 2825 (1998).

6. M.P. Kalachnikov et al., Phys. Rev. A 57, 4778 (1998); P.J. Warwick et al., J. Opt. Soc. Am. B 15(6), 1808 (1998).

7. Y. Li, J. Dunn, J. Nilsen, A.L. Osterheld, and V.N. Shlyaptsev, in this proceedings, SPIE Proceedings 3776, (1999); J. Nilsen, J. Dunn, Y. Li, and A.L. Osterheld, in this proceedings, SPIE Proc. 3776, (1999)

8. S.J. Moon, J. Dunn, A.L. Osterheld, K.B. Fournier, V.N. Shlyaptsev, Y. Li, and J. Nilsen, in this proceedings, SPIE Proc. 3776, (1999).

9. J. Dunn, J. Nilsen, A.L. Osterheld, Y. Li, and V.N. Shlyaptsev, "Demonstration of transient gain x-ray lasers near $20 \mathrm{~nm}$ for nickellike yttrium, zirconium, niobium, and molybdenum”, Opt. Lett. 24, 101 (1999).

10. J.R. Crespo López-Urrutia, and E.E. Fill, "Travelling-wave excitation of an X-ray laser medium", SPIE Proc. 2012, 258-264 (1993); E.E. Fill, and G. Pretzler, "Soft X-ray emission from fs laser plasmas in line focus geometry", SPIE Proc. 2520, 124-132 (1995).

11. G.J. Linford, E.R. Peressini, W.R. Sooy, and M.L. Spaeth, "Very long lasers", Appl. Opt. 13(2), 379-390 (1974).

12. I. Yu. Skobelev, A. Ya. Faenov, B.A. Bryunetkin et al., JETP 108, 1263 (1995).

13. B.J. MacGowan, L.B. Da Silva, D.J. Fields, C.J. Keane, J.A. Koch, R.A. London, D.L. Matthews, S. Maxon, S. Mrowka, A.L. Osterheld, J.H. Scofield, G. Shimkaveg, J.E. Trebes, R.S. Walling, "Short wavelength x-ray laser research at the Lawrence Livermore National Laboratory", Phys. Fluids B 4(7), 2326- 2337 (1992).

14. C.J. Keane, "Soft X-ray Laser Source Development and Applications: Worldwide Progress", SPIE Proceedings 1551, 2-48 (1991).

15. L.B. Da Silva, R.A. London, B.J. MacGowan, S. Mrowka, D.L. Matthews, and R.S. Craxton, "Generation of a 45-ps-duration 15.5-nm x-ray laser", Opt. Lett. 19(19), 1532-1534 (1994). 